\section{Envy in the process of development: Implications for social relations and conflict}

\section{Boris Gershman}

I

ssues of conflict and peace have attracted much attention from economists. Among other factors, control over natural resources, inequality, political regime, and ethno-linguistic fragmentation have been examined as possible determinants of violent conflict, including civil wars. ${ }^{1}$ Culture-broadly defined as values, preferences, norms, and beliefs prevalent in a society-has recently come to the forefront of research on economic development, but its role in either provoking conflict or maintaining peace remains underexplored. This essay focuses on concern for relative standing, envy for short, as an important cultural link between inequality, institutions, development, and conflict. A remarkable feature of envy is that it can be either a source of strife and stagnation or, if channeled properly, an engine for peaceful competition and growth. It can be destructive or constructive.

The essay begins by introducing the main stylized facts on envy and its two sides. It then presents elements of a basic theory that captures in a unified framework the qualitatively different equilibria arising in the presence of envy under alternative socioeconomic and institutional environments. The remainder of the essay discusses the emergence, persistence, and implications of envy-related norms and beliefs, especially the fear-of-envy culture and its relation to social conflict.

Envy and its two sides

The basic assumption of the following analysis is that individuals care about relative, rather than just absolute, economic outcomes such as consumption or wealth Evidence in support for this assumption comes from a vast body of empirical research on happiness and job satisfaction, neuroscience, experimental economics, and various surveys. Direct measurement of the importance of social comparisons is a challenge, but recent studies provide some estimates. For instance, according to the 2006-2007 wave of the European Social Survey, relative income is at least somewhat important for three-quarters of respondents in eighteen European countries. Furthermore, relative standing is correlated with subjective wellbeing, and not just in rich countries, but also in developing regions of the world such as rural areas of Nepal and China. ${ }^{2}$

Mechanically, if a person cares about relative standing, her welfare can be improved in two major ways: by increasing her own outcome and by decreasing the relevant reference outcome. The former option shows the constructive side of envy, while the latter reveals its destructive potential. Not surprisingly, both ways of dealing with envy have been documented in various contexts. Examples of constructive responses include entering the labor force and working longer hours in order to increase relative income and consumption, neither of which involves any violence. Destructive envy manifests itself in aggression observed in experimental settings and survey responses and is also explored in case studies from around the world. In the 2002-2003 wave of the Afrobarometer survey, an impressive average of over 9 percent of respondents in nine African countries named envy/gossip as one of the three most important sources of violent intergroup conflict, alongside religious and ethnic rivalry, disputes over land, and economic hardship. ${ }^{3}$

The destructive potential of envy affects the incentives of those making investment, production, and consumption decisions. A person anticipating an envy-motivated aggressive response to his or her relatively high wellbeing migh behave preemptively to avoid or mitigate the consequences of envy-induced conflict. For this reason, even though people strive for higher relative standing, they might not want to move too far ahead of others.

Since envy can be constructive or destructive, a fundamental challenge is to determine the conditions that pin down its equilibrium role in society. As argued below, this has profound implications for economic performance, welfare, socia relations, and conflict.

\section{The basic theory}

I offer a parsimonious game-theoretic framework that captures the qualitatively different equilibria arising from the two sides of envy and provides a platform to examine the dynamics of envy-related behavior over time.

The interaction at the heart of the stylized "envy game" involves two people or social groups who are each other's relevant reference points. The game consists of two stages. First, each person $i(i=1,2)$ can undertake investment that raises her individual productivity (e.g., human capital acquisition or innovation). The outcome, $Y_{i}$, of such self-improving investment depends on the time devoted to this activity, $L$ $\epsilon[0,1]$, the initial endowment, $K_{i}$, which may include, among other things, wealth, ability, and access to productive resources, and the availability of investment opportunities in the society, $A$. Specifically, the investment function is given by $Y_{i}=A K_{i} L_{i}$. Parameter $A$ may also capture the overall stock of knowledge or the 
technological level that effectively imposes an upper bound equal to $A K_{i}$ on attainable individual productivity. Wealth is unequally distributed and $k=K_{I} / K_{2} \in(0,1)$ captures the degree of initial inequality.

In the second stage of the game, individuals allocate their unit of time between productive and destructive activities. The former converts one's own first-stage investment outcome into output (a consumption good), while the latter disrupts the production process of the other individual. Thus, if person $i$ allocates a fraction $d_{i} \in$ $[0,1]$ of his time to destruction, then person $j$ retains only the fraction $p\left(d_{i}\right)=1 /\left(1+\tau d_{i}\right)$ of his final output, where $i, j=1,2, i \neq j$, and where $\tau>0$ is an institutional parameter reflecting the effectiveness of destructive technology, or the overall level of property rights protection. The time $1-d_{i}$ spent productively yields final output $\left(1-d_{i}\right) Y_{i}$ so that consumption of person $i$ is ultimately given by $C_{i}=p\left(d_{j}\right)\left(1-d_{i}\right) Y_{i}$, which is the portion of final output retained given the destruction intensity, $d_{j}$, on the part of person $j$.

The payoff of each player depends on his relative consumption and first-stage time investment which is costly in terms of leisure: $U_{i}=\left(C_{i}-\theta C_{j}\right)^{I-\sigma} /(1-\sigma)-L_{i}$, where the parameter $\theta \in(0,1)$ captures the strength of envy.

The equilibrium outcome of this envy game is largely driven by the relative returns on engaging in constructive and destructive activities which are affected by a mix of economic, institutional, and cultural characteristics. ${ }^{5}$ On the economic side, two factors are crucial: the level of available peaceful investment opportunities, $A$, and the inequality of initial endowments, $k$ (that eventually translates into unequal investment and production outcomes). Broad opportunities allow individuals to gain more from the time invested in self-improvement which makes it easier for those who are behind to productively catch up with their reference group. Scarce investment opportunities, in contrast, put a limit on upward mobility which may leave aggression as the only feasible path to satisfy envy. Higher inequality makes destructive activity more attractive for the envier trying to improve his relative standing: It lowers the marginal cost of diverting time from production while raising the marginal benefit of engaging in destruction.

The institutional side is captured by the effectiveness of destructive technology, $\tau$. Intuitively, if individual property rights are well-protected, defense technology is accessible and effective, and punishment for disruptive activities is severe and inevitable, then the cost of engaging in destruction is high, thus making it an unlikely response. On the cultural side, what matters is the intensity of social comparisons, $\theta$. It is reasonable to think of this envy parameter as partly shaped by religious and moral teachings, as well as by ideology more generally. Like better property rights protection, weaker comparisons make destructive technology less attractive since it is worthwhile to engage in destruction only to the extent that a person cares about relative standing. In fact, in this simple setup the only potential reason for conflict is envy. In what follows, it is convenient to join the institutional and cultural parameters under the label of "tolerance for inequality." Tolerance is low if property rights are poorly protected and people care a lot about relative standing, and vice versa.

\section{Equilibria}

The scale of investment opportunities, inequality of endowments, and tolerance for inequality jointly determine the unique equilibrium outcome of the envy game. The first type of outcome is a "keeping-up-with-the-Joneses" (KUJ) competition: Everyone invests only in productive activity to satisfy relative standing concerns. Such equilibrium is likely to arise if peaceful investment opportunities are abundant, fundamental inequality is low, and tolerance for inequality is high. Factors favoring productive effort and upward mobility enable the constructive side of envy while blocking its destructive side. The view of envy as an engine of hard work and high spending captured in a KUJ equilibrium is commonly applied to modern consumer economies. ${ }^{6}$

On the other side of the spectrum are societies in which destructive envy is a real threat resulting in envy-avoidance behavior and possibly open conflict. In the "fearof-envy" equilibrium, better endowed individuals rationally underinvest in order to avoid getting too far ahead in the consumption distribution. ${ }^{7}$ Such behavior has been documented in small-scale peasant communities and developing economies around the world. Striking examples described in the literature include avoidance of basic housing improvements, rejection of lucrative jobs and intentional failure to fully collect the harvest, and refusal to adopt agricultural innovations or start a business, all due to the fear of provoking destructive envy. Importantly, in already impoverished communities, the expected envious hostility of neighbors discourages production, wealth accumulation, and consumption beyond subsistence. ${ }^{8}$

To the extent that envy-avoidance strategies are successful, the fear-of-envy equilibrium is still a peaceful one, even as anticipation of hostility has detrimental effects on the creative activity of better-endowed individuals. The fear-of-envy constraint is binding, and so long as the tolerance threshold is not crossed there is no actual destruction. Such "corner outcome" is always feasible in an idealized perfect-information world. But under uncertainty or bounded rationality, or if the cost of fully avoiding envy is too high in terms of foregone consumption, actual destruction might take place and resources are wasted to satisfy envy. The equilibria in which destructive envy is binding tend to arise when peaceful investment opportunities are scarce, fundamental inequality is high, and tolerance for inequality is low, that is, when property rights are not well-protected and social comparisons are strong.

Depending on the type of equilibrium, the marginal effects of envy on economic performance are exactly the opposite. Within the KUJ equilibrium, stronger concern for relative standing encourages investment yielding higher aggregate output, so long as a tolerance for inequality threshold is not crossed and society does not shift into the fear-of-envy region. In contrast, in the fear equilibrium, stronger concern for relative standing discourages investment on part of wealthier individuals, undermining total production. Furthermore, it brings society closer to the region of open conflict. Thus, 


\section{DESTRUCTIVE ENVY}

\begin{tabular}{l|l} 
fear of envy & $\leftarrow$ scarce \\
envy-induced conflict & $\leftarrow$ high \\
envy-avoidance & $\leftarrow$ bad \\
discourage investment & $\leftarrow$ strong
\end{tabular}

CONSTRUCTIVE ENVY

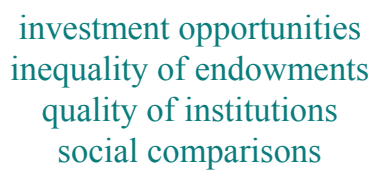
investment opportunities

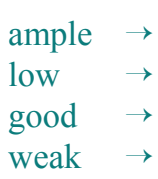

envious emulation

peaceful competition

envy-provocation

encourage investment

Figure 1: Factors affecting the equilibrium role of envy. Source: Based on Gershman (2012).

the equilibrium role of envy in terms of aggregate performance and social conflict depends on the economic, institutional, and cultural environment (see Figure 1).

\section{Welfare}

Since the factors that determine the equilibrium outcome of the envy game are subject to change, so is the dominant side of envy. The above analysis implies that channeling envy into constructive direction is crucial to avoid conflict and foster mobility. Better institutions, broader opportunities, and equal access to those opportunities all work against destructive envy and the fear of it. Why not, then, agree in the first place to adopt better property rights protection or redistribute initial endowments in order to move to a higher-output KUJ equilibrium? Apart from general collective action and political economy considerations, such as commitment problems and the obvious conflict of interests due to the nature of relative standing, the theory points out an additional reason, having to do with the welfare consequences of constructive envy.

The KUJ equilibrium is known to deviate from the first-best equilibrium due to overworking and overspending caused by an envy externality. ${ }^{9}$ Hence, a shift from the fear equilibrium caused by better institutions or ex-ante redistribution of endowments need not be a Pareto improvement if it triggers a "rat race" competition. In fact, everyone might be happier in the fear equilibrium with strictly lower individual consumption. Curiously, the fear of destructive envy might be able to contain the over-stimulating effects of constructive envy.

Clearly, this result is less likely to hold if destructive envy triggers actual conflict and waste of resources. Furthermore, while it makes intuitive sense in the short run, staying in the fear equilibrium causes stagnation that limits future investment opportunities, as discussed below. Since constructive envy stimulates economic growth and raises the productivity of future generations, it leads to gains in social welfare in the long run, potentially making an early institutional transformation and redistribution worthwhile.

\section{From fear to competition}

It follows from the previous discussion that there is a two-way causal relationship between envy and economic activity: Current investment opportunities affect the equilibrium outcome of the envy game (that is, the chosen levels of investment and output) which, in turn, determine future economic opportunities via learning-by-doing and knowledge spillovers, the standard elements of endogenous growth theories and the real world. ${ }^{10}$ Looking at a wide range of societies across the globe, it comes as no surprise that destructive envy and the fear of it are predominant in developing regions, while KUJ-style competition is mostly characteristic of advanced consumer economies. This raises the question of whether there exists a natural development trajectory along which the role of envy evolves over time.

Incorporation of the envy game into a simple growth model, in which future investment opportunities are enhanced by current production, yields the following prediction: While inequality and tolerance parameters fundamentally determine the development path, there is a feedback loop between envy and the growth process. Economic growth shifts the production possibilities frontier and contributes to a switch in the type of equilibrium with regard to envy, and at each point in time the type of equilibrium determines whether envy deters investment or encourages it. Overall, economic growth is instrumental in taking society away from the fear equilibrium, even though high inequality and low tolerance for inequality are serious barriers that may trap an economy in a state of stagnation and envy-induced conflict

Anecdotal evidence suggests that a change in the role of envy is indeed partly driven by expanding economic opportunities. For instance, anthropologist George Foster documents such a transformation in the Mexican village of Tzintzuntzan in the second half of the twentieth century: With the arrival of new opportunities, a by-product of Mexican economic growth, the persistent fear of envy that plagued the community began to dissipate, paving the way to peaceful emulation and sowing the seeds of a consumer society. ${ }^{11}$ 
One can speculate that such a transformation is a more general phenomenon that goes beyond integration of small, traditional communities into larger market economies. At the very least one can see a systematic change in attitudes toward envy over time in a broad range of societies. Condemned by all major world religions as one of the gravest sins, envy has become a favorite tool of advertisers selling products by appealing to the human desire of being envied. Envy-related culture evolves alongside and interacts with the changing economic and institutional environment.

\section{Envy-related cultural norms}

So far, the only cultural element of the theory had to do with the strength of social comparisons, essentially a feature of preferences plausibly influenced by socialization within the family and the larger society. Beyond preferences, there is an important connection between culture and the two sides of envy. Specifically, envy-related behavior corresponding to the dominant role of envy in society becomes curiously embedded in cultural norms and beliefs.

Under "keeping-up-with-the-Joneses," envy-provocation via conspicuous consumption is normal, and the usual response to such behavior is to match the spending pattern of the reference group. Status-seeking via purchases of visible goods and services is, of course, an integral part of consumer culture. Envy is not avoided but rather sought, and envy-provocation is seen as desirable rather than as dangerous. In the context of the above theory, such norm reflects an environment in which destructive envy does not represent a real threat to the envied. As argued earlier, such an environment is characterized by the prospects of upward mobility and strong institutions that are critical in shutting down the destructive side of envy and enabling its constructive side.

When destructive envy is active, however, it is envy-avoidance behavior that becomes the social norm. Culturally, this is manifested in a set of beliefs sometimes collectively called institutionalized envy which includes, among other things, the fear of envy-motivated witchcraft and the evil eye belief. The latter refers to a popular and widespread superstition according to which a mere envious glance can damage the coveted property or the health of its owner. While the evil eye belief is explicitly linked to the fear of envy, witchcraft beliefs are more general in nature, even though envy is consistently named to be one of the main motivations behind acts of witchcraft. Another important difference is that the evil eye belief is largely about unintentional consequences of being envious: It is the supernatural power of envy that causes damage, regardless of what the envier does. In contrast, envy-motivated witchcraft is an intentional act of directed malevolence. Thus, witchcraft beliefs are generally more hostile and are likely to result in open conflict due to witchcraft accusations and ensuing sanctions. ${ }^{12}$

As mentioned in presenting the rational theory of envy, the typical consequence of institutionalized envy is envy-avoidance behavior, manifested in underinvestment,
Table 1: Evil eye belief and inequality in the Standard Cross-Cultural Sample

$$
\text { (1) (2) (3) (4) (5) }
$$

Stratification dummy $0.704 * * 0.744 * * 0.708 * *$

(0.304) (0.301) (0.291)

Specialization

$$
\text { (0.304) (0.301) (0.291) }
$$

Population density

$\begin{array}{llllll}0.019 & 0.139 & 0.090 & -0.022 & 0.120 & 0.086\end{array}$

Urbanization

$\begin{array}{llllll}(0.107) & (0.144) & (0.146) & (0.112) & (0.143) & (0.145)\end{array}$

$\begin{array}{llll}-0.064 & -0.064 & -0.107 & -0.101\end{array}$

$\begin{array}{llll}(0.113) & (0.112) & (0.113) & (0.112)\end{array}$

Settlement patterns $\quad-0.123 \quad-0.131 \quad-0.136 \quad-0.140$

Money

$0.186^{*}$

$\begin{array}{ll}(0.120) & (0.123) \\ & 0.152 \\ & (0.110)\end{array}$

(0.110)

$(0.110)$

Local hierarchy

$-0.173$

$-0.149$

Continental dummies Yes Yes Yes Yes Yes Yes

$\begin{array}{lllllll}\text { Distance controls Yes } & \text { Yes } & \text { Yes } & \text { Yes } & \text { Yes } & \text { Yes }\end{array}$

$\begin{array}{lllllll}\text { Observations } & 186 & 186 & 186 & 186 & 186 & 186\end{array}$

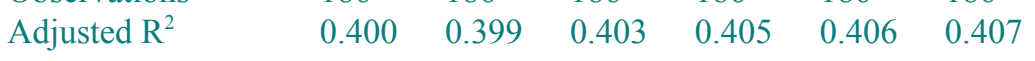

Notes: (a) For variable descriptions and coding, see endnote 15. (b) OLS estimates, robust standard errors in parentheses. (c) $* * *, * *$, and $*$ denote statistical significance at the 1, 5, and 10 percent level, respectively. (d) For alternative specifications, robustness checks, and a detailed description of the data, see Gershman (2013).

concealment, and (preventive) sharing. The only distinction is that it is the supernatural, rather than natural, force of destructive envy that is feared and being avoided. Some of the documented responses to the fear of the evil eye or envy-motivated witchcraft include keeping livestock inside the house to avoid envious glances and limiting the consumption of nonessential "luxury" goods such as eggs and TV sets. Thus, the behavioral responses to the fear of natural and supernatural forces of destructive envy are often observationally equivalent. So, why does the fear-of-envy culture emerge in the first place ${ }^{13}$

Emergence and persistence of the fear-of-envy culture

In another paper, I explore the origins of the evil eye belief but the conceptual analysis 
that follows here might also be applied to similar forms of institutionalized envy. One useful approach to understanding cultural beliefs and values treats them as "fast and frugal" heuristics approximating the right kind of behavior in an uncertain environment in which information is imperfect and learning is costly. If the cost of undertaking a fully rational response is high, a rough guide approximating optimal behavior is adopted. In the rational theory of envy outlined in the first part of this essay, the fear equilibrium requires people to know precisely the tolerance threshold of their reference group, among other things. In practice, of course, such information is not readily available. In addition, in an environment conducive to manifestations of destructive envy, particularly in traditional societies with poor institutional infrastructure, it is crucial to be cautious and to avoid taking the risk of being subject to aggression and violence of any sort. As pointed out by Jared Diamond, behavioral rules that minimize risk in a dangerous environment are worth following even if they might seem overly cautious. ${ }^{14}$

Consistent with the approach to culture summarized in the previous paragraph, the main hypothesis is that the evil eye belief emerged and persisted as a useful heuristic device under conditions that enable the destructive side of envy and thus make envy-avoidance strategies an optimal response to anticipated conflict. According to the theory of envy, such conditions include scarce opportunities for investment and upward mobility, high wealth inequality, and low tolerance for inequality manifested in the effectiveness of destructive technology and strong social comparisons.

I put this hypothesis to the test using the Standard Cross-Cultural Sample, a dataset on 186 pre-industrial societies from around the world, put together by anthropologists over the past few decades. The dataset contains an array of characteristics including an ordinal measure of the prevalence of the evil eye belief and various socioeconomic indicators. A robust outcome of the empirical analysis is a strong positive relationship between the prevalence of the evil eye belief and the proxy measures of wealth inequality. Statistically controlling for a range of potential confounding factors such as spatial diffusion of the belief due to cross-cultural transmission, population density, settlement patterns, and other correlates of early economic development, as well as controlling for continental fixed effects, the main finding is in line with the fear-of-envy theory: More unequal societies are more likely to have a strong belief in the evil eye (see Table 1$).{ }^{15}$

An important property of culture is that it is resistant to change. Cultural beliefs may persist even if the relevant economic and institutional environment has changed, rendering those beliefs inadequate. Not surprisingly, the evil eye belief, as well as witchcraft beliefs, have existed for ages and continue to affect economic decisions and social relations today. In a 2008-2009 survey conducted by the Pew Forum on Religion and Public Life in nineteen countries of Sub-Saharan Africa, over 42 percent of respondents believed in the evil eye with roughly the same proportion believing in witchcraft. Apart from the dire economic consequences of such beliefs due to envy-avoidance behavior, they additionally create an atmosphere of mistrust and erode social capital. ${ }^{16}$ Cultural beliefs based on the fear of destructive envy are often a sign of a latent conflict existing in a community even if they do not turn into an open confrontation such as witchcraft accusations and trials.

Because of the stickiness of cultural beliefs, it is particularly important to create economic and institutional conditions that work against destructive envy, such as prospects of upward mobility, equal access to investment opportunities, and a proper legal infrastructure. As adherence to obsolete cultural norms becomes costlier, they are more likely to transform reducing the tension in social relations and releasing constructive envy.

\section{Conclusion}

Envy is a powerful motive of human behavior that has two sides, constructive and destructive. The dominant role of envy in society is jointly determined by a mix of economic, institutional, and cultural characteristics that channel envy in the direction of either self-improvement or disruptive, antisocial behavior. Policies favoring the former and discouraging the latter include the provision of opportunities for peaceful investment, equal access to those opportunities, as well as security of private property rights. Importantly, the dominance of constructive envy creates a virtuous cycle of envy-driven economic growth that raises social welfare, renders harmful fear-of-envy culture obsolete, and contributes to long-lasting peaceful competition.

Notes

Boris Gershman is an assistant professor of economics at American University, Washington, D.C. He may be reached at < boris.gershman@american.edu>.

1. See Blattman and Miguel (2010) for an extensive overview of theoretical and empirical literature.

2. Vast body of empirical research: For an overview, see Clark, et al. (2008) and Frank and Heffetz (2011). European countries: Clark and Senik (2010). The intensity of social comparisons is estimated to be even higher in Japan (Clark, et al., 2013) Relative standing and subjective wellbeing: Clark, et al. (2008). Nepal: Fafchamps and Shilpi (2008). China: Knight, et al. (2009).

3. Constructive and destructive side of envy: The distinction has a long intellectual history in economics and other social sciences. The more recent references include Elster (1991), Zizzo (2008), and Gershman (2012). Labor force: Park (2010). Longer working hours: Pérez-Asenjo (2011). Aggression: Zizzo (2003). Survey responses: Cuddy, et al. (2007) 
4. See Gershman (2012).

5. For a rigorous derivation of all results presented below see Gershman (2012).

6. See, e.g., Schor (1991); Matt (2003).

7. Other, perhaps less damaging, responses to the fear-of-envy are concealment of wealth and (preventive) sharing.

8. Basic housing improvements: Foster (1979). Rejection: de Vidas (2007). Refusal: Schoeck (1969). Business: Mui (1995). Envious hostility of neighbors: Nash (1970); Dow (1981).

\section{Frank (1985).}

10. In terms of the envy model, one can assume that the current productivity level is a function of aggregate investment in the previous period.

\section{Foster (1979).}

12. Institutionalized envy: Wolf (1955). Motivations behind acts of witchcraft: See, for example, Madsen (1966), Ashforth (2005), and various essays in ter Haar (2007). Witchcraft accusations and ensuing sanctions: To cite a gruesome example available from the official statistics, 3,072 accused witches were killed in Sukumaland, Tanzania, between 1970 to 1988 (Miguel, 2005). More than 600 people were accused of witchcraft and lost their lives in Limpopo Province, South Africa (ter Haar, 2007).

13. Keeping livestock inside the house: Ghosh (1983). Limiting consumption: Madsen (1966).

14. Another paper: Gershman (2013). Behavior in an uncertain environment: Richerson and Boyd (2005); Nunn (2012). Jared Diamond: Diamond (2012, ch. 8).

15. Evil eye belief. Presence of the evil eye belief, coded on an ordinal scale from incontrovertibly absent (1) to incontrovertibly present (8). Stratification dummy. The original class stratification measure comprises five categories: absence of significant wealth distinctions among freemen (1); wealth distinctions based on the possession and distribution of property, not crystallized into distinct social classes (2); elite stratification, in which an elite class has control over scarce resources, particularly land (3); dual stratification into a hereditary aristocracy and a lower class of ordinary commoners or freemen (4); complex stratification into social classes correlated in large measure with extensive differentiation of occupational statuses (5). Class stratification dummy is equal to 0 for the first category and 1 otherwise Specialization. The original technological specialization measure comprises five categories: none (1); pottery only (2); loom weaving only (3); metalwork only (4); smiths, weavers, potters (5). This variable is transformed into an ordinal measure equal to 1 for the first category, 2 for categories (2)-(4), and 3 for the fifth category. It is then multiplied by the class stratification dummy. Distance to Babylon. Great circle distance from the location of an SCCS society, as defined by the geographical coordinates, to the location of Babylon: (32 35'N; 44 45'E). Computed using the Haversine formula and measured in $1000 \mathrm{~km}$. For the New World (North and South America) this measure is set to zero. Distance to Tenochtitlan. Great circle distance from the location of an SCCS society, as defined by the geographical coordinates, to the location of Tenochtitlan: (19N; 9910 'W). Computed using the Haversine formula and measured in $1000 \mathrm{~km}$. For the Old World (excludes North and South America) this measure is set to zero. Distance to coastline. Great circle distance from an SCCS society, as defined by the geographical coordinates, to the closest location on the coastline detected using ArcGis software. Computed using the Haversine formula and measured in $1000 \mathrm{~km}$. Population density. Mean population density in the territory controlled or exploited by an SCCS society, on the following ordinal scale: less than 1 person per square mile (1); 1-5 persons per square mile (2); 5.1-25 persons per square mile (3); 26-100 persons per square mile (4); more than 100 persons per square mile. Urbanization. Average population of local communities, measured on the following ordinal scale: less than 100 persons (1); 100-199 persons (2); 200-399 persons (3); 400-999 persons (4); more than 1000 persons (5). Settlement pattern. A measure of residence fixity, on the ordinal scale: fully nomadic (1); seminomadic (2); semisedentary (3); sedentary but impermanent (4); sedentary and relatively permanent (5). Money. Measures the degree of complexity with respect to media of exchange on the ordinal scale: lack of organized medium of exchange, barter (1); true money is lacking but the society employs domestically usable articles, such as salt, grain, livestock, or ornaments as a medium of exchange (2); the society lacks any form of indigenous money but has long used the currency of an alien people, e.g., that of its colonial rulers (3); indigenous articles of token or conventional value, such as cowrie shells, wampum, or imitation tools, as an elementary form of money (4); indigenous currency in the form of metal coins of standard weight and fineness and/or their equivalent in paper currency (5). Local hierarchy. Jurisdictional hierarchy of the local community, on the ordinal scale: theoretical minimum of two levels, e.g., family and band (1); three levels (2); four levels, e.g., nuclear family, extended family, clan-barrios and village (3). Continental dummies. Indicators for Africa, Eurasia, Oceania, North America, and South America.

16. Golooba-Mutebi (2005). 


\section{References}

Ashforth, A. 2005. Witchcraft, Violence, and Democracy in South Africa. Chicago, IL: The University of Chicago Press.

Blattman, C. and E. Miguel. 2010. “Civil War.” Journal of Economic Literature. Vol. 48, No. 1, pp. 3-57.

Clark, A.E. and C. Senik. 2010. "Who Compares to Whom? The Anatomy of Income Comparisons in Europe.” Economic Journal. Vol. 120, pp. 573-594.

Clark, A.E., C. Senik, and K. Yamada. 2013. "The Joneses in Japan: Income Comparisons and Financial Satisfaction." Working Paper: Paris School of Economics.

Clark, A.E., P. Frijters, and M. Shields. 2008. "Relative Income, Happiness and Utility: An Explanation for the Easterlin Paradox and Other Puzzles." Journal of Economic Literature. Vol. 46, No. 1, pp. 95-144.

Cuddy, A.J., S.T. Fiske, and P. Glick. 2007. "The BIAS Map: Behaviors From Intergroup Affect and Stereotypes." Journal of Personality and Social Psychology. Vol. 92, No. 4, pp. 631-648.

de Vidas, A.A. 2007. "The Symbolic and Ethnic Aspects of Envy Among a Teneek Community (Mexico).” Journal of Anthropological Research. Vol. 63, No. 2, pp. 215-237.

Diamond, J. 2012. The World Until Yesterday: What Can We Learn from Traditional Societies? New York: Viking.

Dow, J. 1981. "The Image of Limited Production: Envy and the Domestic Mode of Production in Peasant Society." Human Organization. Vol. 40, No. 4, pp. 360-363.

Elster, J. 1991. "Envy in Social Life,” pp. 49-82 in R.J. Zeckhauser, ed. Strategy and Choice. Cambridge, MA: MIT Press.

Fafchamps, M. and F. Shilpi. 2008 "Subjective Welfare, Isolation, and Relative Consumption." Journal of Development Economics. Vol. 86, No. 1, pp. 43-60.

Foster, G. 1979. Tzintzuntzan: Mexican Peasants in a Changing World. New York: Elsevier.

Frank, R.H. 1985. "The Demand for Unobservable and Other Nonpositional Goods." American Economic Review. Vol. 75, No. 1, pp. 101-116.

Frank, R.H. and O. Heffetz. 2011. "Preferences for Status: Evidence and Economic Implications," chapter 3 in J. Benhabib, A. Bisin, and M. Jackson, eds. Handbook of Social Economics. New York: Elsevier.

Gershman, B. 2012. "The Two Sides of Envy." Working Paper. Department of Economics. American University.

Gershman, B. 2013. "The Economic Origins of the Evil Eye Belief." Working Paper. Department of Economics. American University.

Ghosh, A. 1983. "The Relations of Envy in an Egyptian Village.” Ethnology. Vol. 22, No. 3, pp. 211-223.
Golooba-Mutebi, F. 2005. "Witchcraft, Social Cohesion and Participation in a South African Village." Development and Change. Vol. 36, No. 5, pp. 937-958.

Knight, J., L. Song, and R. Gunatilaka. 2009. "Subjective Well-Being and Its Determinants in Rural China." China Economic Review. Vol. 20, No. 4, pp. 635-649.

Madsen, W. 1966. "Anxiety and Witchcraft in Mexican-American Acculturation." Anthropological Quarterly. Vol. 39, No. 2, pp. 110-127.

Matt, S.J. 2003. Keeping Up with the Joneses: Envy in American Consumer Society, 1890-1930. Philadelphia, PA: University of Pennsylvania Press.

Miguel, E. 2005. "Poverty and Witch Killing." Review of Economic Studies. Vol. 72, No. 4, pp. 1153-1172.

Mui, V.-L. 1995. "The Economics of Envy." Journal of Economic Behavior \& Organization. Vol. 26, No. 3, pp. 311-336.

Nash, J. 1970. In the Eyes of the Ancestors: Belief and Behavior in a Maya Community. New Haven, CT: Yale University Press.

Nunn, N. 2012. "Culture and the Historical Process." Economic History of Developing Regions. Vol. 27, pp. S108-S126.

Park, Y. 2010. "The Second Paycheck to Keep Up With the Joneses: Relative Income Concerns and Labor Market Decisions of Married Women." Eastern Economic Journal. Vol. 36, pp. 255-276.

Pérez-Asenjo, E. 2011. "If Happiness is Relative, Against Whom Do We Compare Ourselves? Implications for Labour Supply." Journal of Population Economics. Vol. 24, No. 4, pp. 1411-1442.

Richerson, P.J. and R. Boyd. 2005. Not by Genes Alone: How Culture Transformed Human Evolution. Chicago, IL: The University of Chicago Press.

Schoeck, H. 1969. Envy: A Theory of Social Behavior. New York: Harcourt, Brace, and World.

Schor, J.B. 1991. The Overworked American: The Unexpected Decline of Leisure. New York: Basic Books.

ter Haar, Gerrie, ed. 2007. Imagining Evil: Witchcraft Beliefs and Accusations in Contemprorary Africa. Trenton, NJ: Africa World Press, Inc.

Wolf, E.R. 1955. "Types of Latin American Peasantry: A Preliminary Discussion." American Anthropologist. Vol. 57, No. 3 (Part 1), pp. 452-471.

Zizzo, D.J. 2003. "Money Burning and Rank Egalitarianism with Random Dictators." Economics Letters. Vol. 81, No. 2, pp. 263-266.

Zizzo, D.J. 2008. "The Cognitive and Behavioral Economics of Envy,” pp. 190-210 in R.H. Smith, ed. Envy: Theory and Research. New York: Oxford University Press. 